IdeAs

Idées d'Amériques

$16 \mid 2020$

Les marges créatrices : intellectuel.le.s afrodescendant.e.s et indigènes auX Amériques, XIX-XXe siècle

\title{
Anne E. Deysine, Les États-Unis et la démocratie
}

Paris, L'Harmattan, 2019, 262 pages

\section{Katya Long}

\section{OpenEdition}

\section{Journals}

Édition électronique

URL : http://journals.openedition.org/ideas/9852

DOI : 10.4000/ideas.9852

ISSN : 1950-5701

\section{Éditeur}

Institut des Amériques

\section{Référence électronique}

Katya Long, «Anne E. Deysine, Les États-Unis et la démocratie », IdeAs [En ligne], 16 | 2020, mis en ligne le 01 octobre 2020, consulté le 18 octobre 2020. URL : http://journals.openedition.org/ideas/9852 ; DOI : https://doi.org/10.4000/ideas.9852

Ce document a été généré automatiquement le 18 octobre 2020

\section{(c) (i) $\odot$}

IdeAs - Idées d'Amériques est mis à disposition selon les termes de la licence Creative Commons Attribution - Pas d'Utilisation Commerciale - Pas de Modification 4.0 International. 


\title{
Anne E. Deysine, Les États-Unis et la démocratie
}

Paris, L'Harmattan, 2019, 262 pages

\author{
Katya Long
}

\section{RÉFÉRENCE}

Anne E. Deysine, Les États-Unis et la démocratie, Paris, L'Harmattan, collection « Penser le temps présent », 2019, 262 pages.

1 L'ouvrage d'Anne E. Deysine Les États-Unis et la démocratie représente avant tout une contribution bienvenue au champ encore trop réduit de la publication scientifique de langue française sur les États-Unis. Cette contribution tombe à point nommé dans cette période électorale mais également sous la présidence de Donald Trump qui, par sa pratique du pouvoir, interroge les fondements constitutionnels et normatifs de la démocratie américaine.

2 Le livre est construit autour de la question centrale ambitieuse et pleine d'aspérités du rapport des États-Unis à la démocratie et a pour ambition d'établir un état des lieux, voire un diagnostic sur l'état de santé du système politique américain.

Dès l'introduction, le ton est donné. Ce travail s'inscrit dans une approche qui interroge profondément le caractère démocratique de l'expérience américaine bien avant la présidence de l'occupant actuel de la Maison Blanche. Ainsi, l'auteure s'attelle à répondre à trois questions. Il s'agit, tout d'abord, de déterminer la part conjoncturelle dans la détérioration de la qualité de la vie démocratique américaine liée à la présidence Trump et les faiblesses structurelles des institutions. Ensuite, la capacité de ces institutions à résister à la montée du populisme et, enfin, la possibilité pour la société civile de se mobiliser de façon suffisante pour contrer électoralement le mouvement conservateur incarné par le président Trump. L'introduction fait ensuite un retour bienvenu sur les circonstances de l'élection de 2016 qui permet de présenter le contexte des développements qui suivent. Enfin, l'auteure consacre le reste de 
l'introduction à la définition théorique des concepts-clés du livre : l'État de droit, la démocratie et l'érosion des normes.

4 Le cœur de l'ouvrage se décline alors en trois parties que nous allons brièvement présenter. La première s'intéresse à l'érosion des normes sous l'administration de Donald Trump en trois chapitres portant respectivement sur la présidence, les normes écrites (c'est-à-dire la remise en question de l'équilibre des pouvoirs) et enfin les normes et les traditions non écrites (le chapitre 3 où l'auteure se penche également sur l'atteinte aux normes que l'on pourrait qualifier de « savoir- vivre »). Deux idées fortes se dégagent de cette partie de l'ouvrage : Donald Trump ne fait que pousser à l'absurde des tendances déjà présentes au cœur du système institutionnel américain caractérisé par un renforcement toujours croissant du pouvoir exécutif, et en particulier du pouvoir présidentiel, au détriment des formes de contre-pouvoirs institutionnels ou normatifs ; et la faiblesse des institutions face à cet assaut.

5 La deuxième partie de l'ouvrage propose, là aussi en trois chapitres, un état des lieux de la résistance (ou plus exactement des tentatives de résistance) des institutions américaines à l'érosion des normes et à la dégradation de la démocratie. Alors que le travail de contre-pouvoir du Congrès (certes limité par le contrôle de l'une des deux chambres par le parti présidentiel) est plutôt bien connu, tout comme la place importante du pouvoir judiciaire dans le système de "checks and balances", le deuxième chapitre de cette partie (chapitre 5) s'attarde sur un élément du système politique américain souvent ignoré de ce côté de l'Atlantique: les freins présents au sein même du pouvoir exécutif. L'auteure expose tout d'abord les limites au pouvoir de Donald Trump créées par la désorganisation même de son administration, du fait de son rejet des normes qui gouvernent habituellement le travail au sein de la Maison Blanche. Vient ensuite une présentation très utile des instruments mis en place par le Congrès au cœur du pouvoir exécutif afin d'y empêcher d'éventuels abus.

6 De la troisième partie, composée dans une belle symétrie de trois chapitres, on retiendra un portrait sans concession du dépérissement démocratique des États-Unis : un bref rappel historique des tensions autour du droit de vote, notamment celui des noirs, précède un exposé factuel des diverses attaques contre l'intégrité du vote, du système représentatif et les droits des minorités ethniques ou sexuelles qui minent la démocratie américaine. S'ensuit un développement (chapitre 8) sur le lien entre système économique, dérégulation et qualité démocratique. L'auteure avance ainsi que l'absence ou la faiblesse des normes encadrant l'action politique des milieux financiers et économiques, ajoutée aux fortes inégalités au sein de la société américaine, sapent les fondements d'une vie politique saine. Le dernier chapitre de l'ouvrage se penche, quant à lui, sur la "contagion du mauvais exemple", autrement dit sur les conséquences internationales de l'étiolement démocratique des États-Unis. À notre avis, il s'agit là de l'un des apports centraux de ce livre et qui en fait l'originalité. L'imbrication des valeurs que l'Amérique proclame depuis son indépendance et son leadership international restent un élément-phare de la politique étrangère américaine. Anne Deysine démontre ici que la crise démocratique que traversent les États-Unis ne concerne pas seulement leurs citoyens mais doit nous interpeller tous, tant l'absence américaine fragilise l'ordre normatif international.

7 Enfin, dans la conclusion, l'auteure dessine des lignes de fuite en abordant le rebond du parti démocrate aux élections de mi-mandat en 2018 et les espoirs d'un résultat favorable lors des élections présidentielles du 3 novembre 2020. 
8 Si ce livre pédagogique et clair comble un manque dans les publications francophones portant sur le système politique américain, on peut regretter la façon relativement succincte avec laquelle est abordée une certaine renaissance de la démocratie américaine forgée par l'expérience de la présidence de Donald Trump. En effet, les ressources qui pourraient être annonciatrices d'un renouveau démocratique se laissent deviner dans un mouvement social qui retrouve de sa puissance autour d'un courant social-démocrate incarné par des individualités charismatiques mais porté par une organisation sans précédent de la société civile, car « là où croît le péril croît aussi ce qui sauve ».

\section{AUTEURS}

\section{KATYA LONG}

Chercheuse associée au Centre AmericaS, Université libre de Bruxelles 